\title{
Transformações no mundo do trabalho, no estado nas políticas públicas e as novas demandas para o serviço social
}

\section{Changes in labor, in government, in public policies and the new demands of the social work}

DOI: $10.46919 / \operatorname{archv} 1 \mathrm{n} 1-003$

Recebimento dos originais: 01/01/2020

Aceitação para publicação: 10/01/2020

\author{
Raquel Bergmann Behr \\ Assistente social especialista em Administração Pública e em Gestão de Recursos Humanos no Serviço \\ Público \\ Prefeitura Municipal de São José dos Pinhais \\ Endereço: R. Passos de Oliveira, 1101 - Centro, São José dos Pinhais - PR \\ E-mail: raquel.behr@sjp.pr.gov.br
}

\section{RESUMO}

O presente trabalho tem como objetivo apresentar as principais mudanças na forma de produção na sociedade brasileira, desde os anos 60 até a contemporaneidade, partindo da compreensão de como estas mudanças afetaram o modo de viver da sociedade, e a consequente reprodução social da classe trabalhadora. Neste sentido, trataremos também da formação acadêmica em Serviço Social, e o que a sociedade contemporânea, em decorrência às alterações no padrão de produção, traz como demanda e exigências para esta atividade profissional. Para abordagem de tal tema, utilizamo-nos da metodologia de pesquisa bibliográfica e eletrônica.

Palavras-chave: Modo de produção, transformações societárias, classe trabalhadora, Capitalismo, serviço social

\begin{abstract}
The present work aims to present the main changes in the form of production in Brazilian society, from the 1960s to contemporary times, part of the understanding of how these changes affect the way of life of society and affect the social reproduction of the working class. In this sense, also dealing with academic training in Social Work, or contemporary society, due to changes in the production pattern, brings demand and use for this professional activity. To address this issue, use bibliographic and electronic research methods.
\end{abstract}

Keywords: Production mode, corporate transformations, working class, Capitalism, social service

\section{INTRODUÇÃO}

O capitalismo, na sua fase atual, assume novas configurações devido as alterações sofridas nos modos de produção do taylorismo para o toyotismo. Por sua vez, a passagem do Estado de Bem-Estar Social ao Estado Neoliberal, mostra-se como uma consequência da transição nos modos de produção, sendo que o Estado Neoliberal é caracterizado prioritariamente pelas políticas de privatizações. 
Para a melhor compreensão destas transformações societárias traremos uma revisão bibliográfica referente às mudanças no modo de produção na sociedade brasileira, desde os anos 60 até a contemporaneidade, e consequentemente abordaremos as principais mudanças ocorridas no mundo do trabalho e na esfera Estatal.

Diante deste novo cenário, cabe a reflexão acerca das novas exigências para o fazer profissional do serviço social. Para tanto, faremos uma análise das transformações ocorridas no cotidiano do trabalho dos profissionais de serviço social derivados destas transições societárias.

Para abordagem do tema, utilizou-se a metodologia de pesquisa bibliográfica e eletrônica.

\section{PRINCIPAIS TRANSFORMAÇÕES DA CONTEMPORANEIDADE: MUNDO DO TRABALHO, ESTADO E SERVIÇO SOCIAL}

A partir de meados da década de 70 ocorreram significativas mudanças na sociedade que afetaram com rigor o mundo do trabalho, a esfera do Estado e a sociedade civil, o que redefiniu a estrutura e organização do país.

Para compreender as transformações e os impactos sofridos pela classe trabalhadora e no trabalho do assistente social, torna-se necessário entender o contexto histórico que proporcionou o estágio atual da sociedade.

\subsection{O MUNDO DO TRABALHO}

Por volta dos anos 60 e 70, o Brasil vivia um amplo período de acumulação do capital dado pelo Fordismo. O Fordismo é entendido pela forma como a indústria e o processo de trabalho consolidaram-se, cujos elementos constitutivos básicos eram dados pela produção em massa, através da linha de montagem e de produtos mais hegemônicos; "através do controle dos tempos e movimentos pelo cronômetro taylorista e da produção em série fordista; pela existência do trabalho parcelar e pela fragmentação das funções [...] entre outras dimensões. " (ANTUNES,2008, p. 24-25)

Característica importante deste período, mostra-se pelo sindicalismo fortalecido e reivindicador. Por melhores condições de trabalho, a classe assalariada se organizava realizando grandes greves, que culminaram em amplas conquistas.

Entretanto, na década de 70, o capitalismo entra em colapso, devido à crise do petróleo, e como resposta à crise estrutural, são intensificadas as alterações no processo produtivo, associados ao avanço tecnológico. Com a alteração na forma e no modelo de produção, percebeu-se forte impacto no mundo do trabalho.

Assim, começa a surgir um novo modelo de produção, o toyotismo. Neste modelo a produção “[...] é voltada e conduzida diretamente pela demanda. A produção é variada diversificada e pronta para 
suprir o consumo." (ANTUNES,2008, p.32). Essa flexibilidade dado ao processo produtivo busca atender às exigências mais individualistas postas pelo mercado, o que requer trabalhadores polivalentes.

Associado à essa flexível forma de produção ocorre a Revolução informacional, revolução que vem alterar a forma de produzir. Com o surgimento dessas novas tecnologias, redefine-se as relações de trabalho.

Assim sendo, no toyotismo o trabalho passa a ser realizado por uma equipe de trabalhadores, mas com uma estrutura da equipe com número de operários reduzido, que será ampliado pela realização de horas extras. A diminuição da quantidade de pessoas em trabalho formal, originou formas de contratação precárias e flexíveis. Os contratos temporários e os serviços terceirizados também são importantes características desse novo modo de produção.

Além disso, as novas referências culturais, afetam a classe trabalhadora de forma a promover o distanciamento dos vínculos de pertencimento de uma classe. É notável a desarticulação dos sindicatos no mundo atual, na qual o sindicalismo frequentemente passou a apelar à institucionalização e a burocratização como características: a burocracia social sindical.

Tais alterações criaram, portanto, uma classe trabalhadora com vínculos fragilizados, de composição fracionada, classificando os trabalhadores entre qualificados e desqualificados, com vínculos empregatícios formais e informais. Estas alterações afetaram a classe trabalhadora visto que há uma parcela dos trabalhadores compreendem a intelectualizarão do trabalho, despontando o trabalhador polivalente, multifuncional. Para outra parcela dos trabalhadores as relações de trabalho precarizam-se ainda mais, fazendo com que o trabalhador permaneça em caráter temporário ou somando o desemprego estrutural.

David Harvey (1993) discute o tema abordado, em torno das consequências oriundas da adoção do modo de produção no capitalismo contemporâneo. O autor refere que neste tema, está intrínseco ao aumento considerável no exército de trabalhadores sobrantes, trazendo ênfase ao debate acerca do desemprego estrutural, da consequente precariedade dos contratos trabalhistas e terceirizações, o que vem desestruturar o arsenal legislativo com relação aos os direitos trabalhistas e sociais.

\subsection{NA ESFERA DO ESTADO}

Entre as décadas de 50 e 70 o capitalismo viveu os anos dourados, ampliando-se para além das fronteiras nacionais, superando as estratégias de regulação do Estado. Entretanto nos anos 70, com a crise do petróleo, a crise mundial que afetou categoricamente a economia brasileira, a dinâmica da acumulação capitalista entrou em confronto com o regulacionismo do Estado.

A partir de então, passa a ser defendida a ideia de reestruturação do Estado, que passa a ser entendida como Estado Neoliberal. Essa reforma do Estado, defende a redefinição do papel do Estado, 
reduzindo assim a sua abrangência. Nesse sentido, as atividades na área econômica, social e científica são consideradas como não exclusivas do Estado.

Com a intenção de redução dos gastos públicos, o Estado transfere responsabilidades para o mercado, justificando assim, a privatização, a terceirização e passa a compartilhar a gestão com o mercado e a sociedade civil, defendendo a participação dos cidadãos, na gestão das políticas públicas.

As mudanças ocorridas no âmbito o Estado, afetam diretamente a sociedade civil considerando a mercantilização dos direitos sociais, pois, ao expandir a execução dos serviços sociais ao mercado, desvincula-se a garantia de qualidade dos mesmos, visto que as ações são prestadas de forma fragmentada, pontual, no sentido filantrópico.

Nesse sentido, a reforma do Estado foi pensada apenas com intuito de reduzir os custos, sem considerar os direitos sociais afirmados pela Constituição Federal de 1988.

Dada tal responsabilidade, os cidadãos são lesados na medida em que as políticas públicas tornamse focalizadas, e até mesmo proporcionadas numa visão de filantropia. Desta forma, o Estado que é direcionado pela sociedade civil, criado para atender as suas necessidades, é deslocado da mesma, o que provoca o distanciamento do Estado da sociedade civil que o gera e o determina.

\subsection{O SERVIÇO SOCIAL}

Manter o processo de formação profissional sob permanente e crítica atualização, torna-se cada vez mais uma necessidade dos diferentes campos profissionais. Na conjuntura em que o modo de produção capitalista busca permanecer vigente, se articulando na superação de suas crises, pausas para discussões e reflexões em torno na formação acadêmica dos assistentes sociais , tornam-se prioridade, objetivando tornar claro, o real significado da profissão, que varia de acordo com a mudança de paradigmas, do objeto de trabalho profissional, e da opção pela corrente teórica que os assistente sociais adotam para a construção e implementação aos projetos societários.

Considerando a articulação do modo de produção capitalista que rompe as barreiras de sua continuidade, cabe aqui ressaltar o processo de ajustamento do sistema de educação ao modo de produção vigente. Esta adequação, passa por dentro da contra-reforma do Estado, em conexão ao ajuste neoliberal que se iniciou na América Latina nos anos de 1970, e no Brasil na década de 90.

Nesse sentido, ao findar os anos 90, a educação superior aparece no mundo mercantil como campo dos mais promissores ao lucro. "Mais rentável do que a bolsa de Londres [...] mais do dobro do mercado mundial do automóvel. " (SOUZA SANTOS, 2004, p.27). Ou seja, essa parafernália inconstitucional, empurra a universidade pública seu corpo docente e técnico administrativo, o ensino de graduação, a pesquisa, a extensão e a pós-graduação para a esfera mercantil. 
Iamamoto (2007) apresenta dados do MEC, de abril de 2007, onde apenas 6 cursos de graduação em serviço social EaD disponibilizam 9.760 vagas.

A expansão mercantilizada, todavia, não foi capaz de suprir as necessidades do país. Na faixa etária entre 17-24 anos, a taxa nacional de matrícula no ensino superior em 2005, era de 11,5\%. Abaixo da Argentina, do Equador, Costa Rica, Venezuela, Peru, Uruguai, Chile, Bolívia, Colômbia e México (BRASIL,2005).

Coagido de um lado, pela demanda proveniente do ensino médio, e de outro pelas exigências da proposta neoliberal, responsabilizadas de organizar um mercado educacional mundial, o Plano Nacional de Educação estabeleceu o objetivo de, em 2011, o Brasil estar com 30\% dos jovens entre 17 - 24 anos, incluídos no sistema de educação de nível superior. Ainda assim, uma porcentagem muito inferior, ao que se percebe nos países do centro do capitalismo.

Com relação a isto, Associação Brasileira de Ensino e Pesquisa em Serviço Social (ABEPSS) que congrega as unidades acadêmicas da graduação e pós-graduação em Serviço Social, o conjunto Conselho Federal (CFESS) e Conselhos Regionais de Serviço Social (CRESS), órgãos de regulamentação e fiscalização da profissão, e a Executiva Nacional dos Estudantes (ENESSO), articulam gestões junto ao MEC com intuito de coibir e evitar a realização de cursos de graduação em EaD em Serviço Social.

A justificativa é de que a modalidade de Ensino à Distância não atende as exigências constantes das Diretrizes Curriculares, e mostram-se inadequadas ao projeto pedagógico e profissional.

A reforma educacional em curso, levanta questões ético-políticas graves, como a apontada por Fétizon e Minto (2007, P.101), de que qualquer indivíduo obrigado a se autoconstruir abaixo da cultura de seu tempo construir-se-ia infra-histórico- irremediavelmente abaixo de sua condição de humanidade [...] aquém de sua condição histórica - autoconstruído e confinado numa infra - humanidade.

Para os autores Fétizon e Minto (2007, P.101) as consequências sofridas pela educação dentro da contrareforma do Estado pode trazer desastrosas perdas no sentido que:

Ao transformar a educação em objeto mercantil, o aluno em cliente consumidor e a universidade em emitente de diplomas banais, essa reforma esvazia a dimensão emancipadora da educação, e subtrai o caráter universalista da instituição universitária.

Ambiente institucional danificado, de ethos acadêmico degradado, ao se constituir lugar da formação acadêmico-profissional das novas gerações, torna-se também, solo de disputa e resistência aos processos de socialização do atual padrão societário.

\section{CONSIDERAÇÕES FINAIS}


A pós modernidade é caracterizada por alterações significativas provocadas na cultura como a troca de valores, o respeito ao consumo, entre outras que levam o ser humano a viver uma época de incertezas.

No nível do conhecimento, a modernidade explica o mundo pela razão, já a pós-modernidade, apresenta uma tendência de fragmentação do sujeito, a não compreensão da realidade em sua totalidade.

As transformações desenfreadas, que têm sofrido a sociedade contemporânea trazem como decorrência a globalização, a Contra-reforma do Estado, a crise da modernidade ou dos paradigmas. A força destrutiva do sistema de acumulação capitalista, e a relação que ela representa, aparece como determinação.

Forte característica da atual fase do capitalismo é a brutal ofensiva sobre o mundo do trabalho e o empenho no sentido de impor maior domínio e subordinação aos trabalhadores, subsumindo sua existência de classe. (DIAS, 1999; GURGEL,2003). Essas medidas, deterioram nosso país, sobretudo as condições de vida das classes subalternizadas.

A educação superior reeditando a lógica fordista do consumo massivo, e as universidades federais transformadas em "escolões pós -médio" passam a emitir certificados genéricos e com mérito duvidoso, que além de descaracterizar as profissões nas discussões dadas, apresentam discutível serventia para o exercício profissional nas diferentes áreas.

Em contrapartida, o projeto pedagógico que a profissão de serviço social vem construindo para a formação de seus quadros, cujo marco é o currículo/82, seguido das atuais diretrizes curriculares, vinculase à uma concepção de educação e de sociedade referenciada na "construção de uma nova ordem societária, sem dominação/exploração de classe, etnia e gênero" o que supõe a erradicação de todos os processos de exploração, opressão e alienação", princípios balizadores do código de ética do assistente social.

A essência profissional libertadora do serviço social, não provém da origem da profissão, muito pelo contrário, têm suas raízes em lutas históricas, tecidas pela sociedade em busca de direitos sociais e trabalhistas. Direitos estes provenientes nas mudanças dos modos de produção, o que resultou em condições sociopolíticas que possibilitaram e impulsionaram os sujeitos profissionais a reelaborar um projeto profissional crítico que, em seu desenvolvimento rompe com as matrizes conservadoras do Serviço Social (IAMAMOTO,1992; NETTO,1996).

Porém, foi nos anos de 1990, que o projeto profissional do serviço social se consolida no país, no período em que emerge a luta contra a ofensiva neoliberal, pela qual passa o Estado brasileiro.

As modificações ocorridas na percepção do que seria responsabilidade do Estado, significaram grandes retrocessos às reivindicações dos trabalhadores, desmantelando condições de trabalho, 
desarticulando estruturas organizativas, reduzindo e aniquilando direitos sociais aos mínimos de condições de vida.

Considerando esta renovada reflexão da profissão, com atores respaldados por um projeto éticopolítico, esta categoria profissional, suas instituições universitárias professores e alunos, supervisionados e amparados por suas entidades representativas (CRESS, CFESS e ENESSO), apresentaram-se, à entrada dos anos 90, para um amplo repensar coletivo e democrático da profissão. Cabia redimensionar o projeto profissional, a partir de então denominado projeto ético-político, frente às alterações do mundo do trabalho, nas manifestações da questão social, nas práticas do Estado e suas relações com as classes sociais.

A concepção de questão social mais difundida no Serviço Social é a de Carvalho e Iamamoto, (1983, P.77)

\begin{abstract}
A questão social não é senão as expressões do processo de formação e desenvolvimento da classe operária e de seu ingresso no cenário político da sociedade, exigindo seu reconhecimento como classe por parte do empresariado e do Estado. É a manifestação, no cotidiano da vida social, da contradição entre o proletariado e a burguesia, a qual passa a exigir outros tipos de intervenção mais além da caridade e repressão.
\end{abstract}

A luta dos trabalhadores e das populações subalternizadas, e as consequentes respostas, como o avanço das organizações, vêm alterar as expressões da questão social. Ou seja, se na fase ditatorial brasileira pós-64, a demanda emergente era libertar-nos da dominação política, hoje a luta é pela consolidação da democracia e a prática dos direitos de cidadania.

Nesse sentido, considerando que a questão social se expressa em suas refrações (NETTO,1992), ao passo que os sujeitos sociais articulam processos para o seu enfrentamento, a essência dessas expressões reside na forma com que os atores se constituem para produzir num específico período histórico e as consequências que trará este processo, na esfera da reprodução.

O grande desafio é salvanguardar as conquistas que conferem legitimidade intelectual, moral e cultural à profissão e fazê-la avançar. Nesse sentido, a conexão entre as transformações societárias e a necessidade de atualização no processo de formação profissional parece óbvia. 


\section{REFERÊNCIAS}

ABEPSS - Texto de referência para a proposta de avaliação da implementação das Diretrizes curriculares do curso de Serviço Social 2005.

ABREU, Marina M.; LOPES, Josefa B. Formação Profissional e Diretrizes curriculares. Inscrita, Brasília, n.10, CFESS, mês 2007.

BEHRING, Elaine, R. Brasil em contra-reforma: desestruturação do Estado e perda de direitos, São Paulo: Cortez,2003.

BEVERIDGE, Sir W. O Plano Beveridge: relatório sobre o seguro social e serviços afins. Rio de Janeiro: José Olímpio,1943.

BOSCHETTI, Ivanete. O desenho das diretrizes curriculares e dificuldades na sua implementação. Temporalis, Porto Alegre, n.8, ABEPSS 2004.

BOSCHETTI, I. A Reforma da Previdência Social no Brasil e os impactos sobre o mercado de trabalho. Serviço Social e Sociedade, São Paulo, v.70, p114-139,2002.

BRAZ, Marcelo. O governo Lula e o projeto ético político do Serviço Social. Serviço Social e Sociedade, n. 78, jul.2004.

BRASIL. Exposição de motivos. Anteprojeto da Lei da Educação Superior. Brasília, 9 de julho de 2005.

NETTO, José Paulo. Cinco notas a propósito da “questão social” In: Revista Temporalis 